Portland State University

PDXScholar

\title{
Assessing the Prediction Potential of an in Silico Computer Model of Intracranial Pressure Dynamics
}

Wayne Wakeland

Portland State University, wakeland@pdx.edu

Rachel Agbeko

Portex Unit Institute of Child Health

Kevin Vinecore

Oregon Health and Science University

Mark Peters

Portex Unit Institute of Child Health

Brahm Goldstein

Oregon Health and Science University

Follow this and additional works at: https://pdxscholar.library.pdx.edu/sysc_fac

Part of the Biomedical Engineering and Bioengineering Commons Let us know how access to this document benefits you.

\section{Citation Details}

Wakeland, W., Agbeko, R., Vinecore, K., Peters, M., \& Goldstein, B. (2009). Assessing the prediction potential of an in silico computer model of intracranial pressure dynamics. Critical care medicine, 37(3), 1079-1089.

This Post-Print is brought to you for free and open access. It has been accepted for inclusion in Systems Science Faculty Publications and Presentations by an authorized administrator of PDXScholar. Please contact us if we can make this document more accessible: pdxscholar@pdx.edu. 


\title{
Assessing the Prediction Potential of an In Silico Computer Model of Intracranial Pressure Dynamics
}

\author{
Wayne Wakeland, $\mathrm{PhD}^{1}$ \\ Rachel Agbeko, $\mathrm{MD}^{2}$ \\ Kevin Vinecore, $\mathrm{BS}^{3}$ \\ Mark Peters, MRCP, $\mathrm{PhD}^{2,4}$ \\ Brahm Goldstein, $\mathrm{MD}^{5}$
}

${ }^{1}$ Systems Science Graduate Program, Portland State University, Portland, OR, USA

${ }^{2}$ Critical Care Group, Portex Unit Institute of Child Health, London, UK

${ }^{3}$ Pulmonary and Critical Care Medicine, Oregon Health \& Science University, OR, USA

${ }^{4}$ Paediatric Intensive Care Unit, Great Ormond Street Hospital for Children NHS Trust, London, UK

${ }^{5}$ Novo Nordisk, Inc. Princeton, NJ, USA

Address for correspondence:

Wayne Wakeland, PhD

Systems Science Graduate Program, SYSC

Portland State University

P.O. Box 751

Portland, OR 97207

Email: wakeland@pdx.edu

Tel.: 503.725.4975

Fax: 503.725.8489 


\begin{abstract}
Objective: Traumatic brain injury (TBI) frequently results in poor outcome, suggesting that new approaches are needed. We hypothesized that a patient-specific in silico computer model of ICP dynamics may predict the ICP response to therapy.
\end{abstract}

Design: In silico model analysis of prospective data.

Stetting: 16-bed pediatric intensive care unit in a tertiary care academic hospital.

Patients: 9 subjects with severe TBI undergoing ICP monitoring (7M/2F, age range $3-17$ years).

Interventions: Random changes in head-of-bed $(\mathrm{HOB})\left(0^{\circ}, 10^{\circ}, 20^{\circ}, 30^{\circ}, 40^{\circ}\right)$ elevation and respiratory rate (to achieve a $\triangle \mathrm{ETCO} 2= \pm 3-4 \mathrm{mmHg}$ ) daily as long as an ICP monitor was in place.

Methods and Main Outcome Measures: A 6-compartment dynamic ICP model was constructed based on data from the interventions and session-specific model parameters were estimated. The accuracy of session-specific model-calculated ICP was compared to the accuracy ICP calculated using non-session specific parameter values. To assess the prediction accuracy of the model, two analyses were performed: a "within" session analysis of Segment A for model estimation and Segment B for prediction, and a "between" session analysis to predict later session ICP using parameters from $\geq 1$ earlier sessions. A mean absolute error to mean absolute deviation ratio (MAE/MAD) of $<1$ was considered favorable.

Results: For non-session specific parameters, MAE/MAD was $<1$ in 2/24 (8\%) sessions. For session-specific parameter values MAE/MAD was $<1$ in $21 / 24(88 \%)$ sessions, and $<0.5$ in $9 / 24$ (38\%) sessions. Sessions with low $(<12 \mathrm{~mm} \mathrm{Hg})(\mathrm{N}=8 ; 33 \%)$ or high $(>18 \mathrm{~mm} \mathrm{Hg})(\mathrm{N}=6 ; 25 \%)$ ICP had lower error than moderate ICP $(12-18 \mathrm{mmHg})(\mathrm{N}=10 ; 42 \%)$. MAE/MAD was $<1$ for $6 / 22(27 \%)$ for within-session predictions and 3/31 (10\%) for between-session predictions. 
Conclusions: The protocol for collecting physiologic data in subjects with severe TBI was feasible and without undue risk. The in silico ICP model with session-specific parameters accurately reproduced actual ICP response to changes in HOB and RR. We demonstrated modest success at predicting future ICP within a session and to a lesser extent between sessions.

Keywords: Computer modeling, in silico, prediction, traumatic brain injury, intracranial pressure 


\section{Introduction}

Traumatic brain injury (TBI) is the leading cause of death and disability in children under 18 years old, causing more than $50 \%$ of all childhood deaths. Each year, more than 150,000 pediatric brain injuries result in about 7,000 deaths and 29,000 children with new, permanent disabilities. The death rate for severe TBI (defined as a Glasgow Coma Scale score $\leq 8$ ) remains between $30 \%-45 \%$ at major children's hospitals $(1,2)$. A published evidence-based medicine review reports that elevated pressure in the brain (ICP) is a main determinant of outcome following TBI and is strongly correlated with both death and disability (3). The underlying mechanism is that persistent elevated ICP leads to reduced blood flow, which can results in insufficient tissue perfusion (ischemia), secondary injuries, and generally poor outcomes.

Despite the availability of many treatment options for reducing elevated ICP (defined as $\geq 20 \mathrm{mmHg})(3)$, poor outcomes frequently result, often due to elevated ICP that is unresponsive to therapy. Treatment options for severe TBI include: draining cerebral spinal fluid (CSF) via a ventriculostomy catheter, raising the head-of-bed (HOB) elevation to $30^{\circ}$ to promote jugular venous drainage, and inducing mild hyperventilation $(2,4,5)$. The underlying pathophysiologic mechanisms governing ICP regulation and the mechanisms by which various treatments affect ICP remains only partially understood (6). It is generally accepted that HOB directly impacts arterial and venous pressure by changing the elevation of the head relative to the heart. The mechanism by which changes in respiration and $\mathrm{PaCO}_{2}$ affect ICP is more complex, invoking an autoregulatory reflex that reduces intracranial blood volume, which reduces pressure. These relationships are discussed further in the methods.

We suggest that new approaches are needed to help improve diagnosis, treatment, and outcome following severe TBI. One candidate approach is to develop and utilize patient-specific in silico computer models of ICP dynamics that "learn" from direct patient data and then may be 
queried to predict the likely ICP response to a specific therapeutic intervention. Computer models of ICP dynamics have been reported in the literature whose behavior has been shown to match historical data almost exactly $(7,8)$. However, to our knowledge there are no reports of using these models to predict an individual patient response. Furthermore, it is not known whether computer models are capable of doing this. But we believe that to do so would require annotated data indicating the exact timing of treatment changes as well as a robust model that incorporates a database of pathologic and treatment variables.

Therefore, we hypothesized that we could build a novel in silico computer model of dynamic ICP changes that could accurately reproduce historical changes from a physiologic database and that this model could be used to predict ICP changes in response to different treatments. The treatment options we studied are changes in the HOB and inducing mild hyperventilation by changing the respiration rate (RR). This is because they are non-invasive, easily adjusted in terms of degree, and easily reversed if necessary for subject safety.

\section{Methods}

This study was approved by the Institutional Review Board of Oregon Health \& Sciences University and the Institute of Child Health/Great Ormond Street Hospital (GOSH) Research Ethics Committee. A prospective clinical research protocol was used to create mild physiologic challenges for pediatric severe TBI patients who had ICP monitoring devices inserted as part of their clinical care was followed.

\section{Physiologic Signal Data Acquisition and Physiologic Challenge Protocol}

Physiologic signals and parametric data were recorded continuously, and precise annotations were captured regarding the exact timing of protocol events using the Physiologic 
Data Acquisition System (PDAS) as previously described (9). In many cases, multiple sessions were recorded on different days. Signals recorded included electrocardiogram, respiration, arterial blood pressure, ICP, and arterial oxygen saturation. The ICP signal was captured at 125 Hz. Since the model sought to capture only the time behavior of mean ICP, the high-frequency components of the signal were ignored. Therefore, the data was decimated and a low-pass filter was applied, yielding smoothed data at a sample rate of $5 \mathrm{~Hz}$, which removed most of the pulsatile component. This data was still noticeably more complex than the output of the model, but preliminary research showed that further simplification threatened to remove important features of the ICP signal.

The response of the subject to the physiologic challenges was used to perturb the system from a resting or steady state and thus estimate patient-specific parameters to build a computer model of intracranial pressure dynamics (the "test" data set). The patient-specific dynamic computer model was then used to predict the patient's response to subsequent challenges, both at later time points within the same session, and also during subsequent sessions (the "validation" data sets).

The two physiologic challenges listed below were randomly administered over a 2-3 hour period for as long as a subject had an ICP monitoring device in place and was clinically stable as determined by the attending ICU physician. The challenges included:

1. Altering the head of the bed (HOB) elevation in random order between $0^{\circ}$ to $40^{\circ}$ in increments or decrements of $10^{\circ}$ at 10 -minute intervals.

2. Increasing minute ventilation (hyperventilation) or decreasing minute ventilation (hypoventilation), in random order, while keeping the tidal volume fixed to achieve an end-tidal $\mathrm{CO}_{2}\left(\mathrm{ETCO}_{2}\right)$ of $[+3$ to +4$] \mathrm{mmHg}$ from baseline values. At each target $\mathrm{ETCO}_{2}$, $\mathrm{PaCO}_{2}$ was checked via arterial blood gas to ensure that the ETCO2 reflected accurate 
changes in actual $\mathrm{PaCO}_{2}$. If not, then minute ventilation was further adjusted, and $\mathrm{ETCO}_{2}$ and $\mathrm{PaCO}_{2}$ were rechecked at each target level of hyper- and hypoventilation was maintained for 15 minutes.

\section{ICP Dynamic Model}

The model of ICP dynamics used in this study was patterned after models previously reported by our research group (11-13). Since the underlying physiology is very complex and not completely understood, the mathematical model is necessarily highly simplified. The model consisted of six differential (rate) equations for three blood volume compartments plus the CSF fluid volume in aggregate, the brain tissue volume (which could be normal or edematous), and when appropriate, an intra- or extra-cranial hematoma volume. The pressure in each compartment was calculated by the model based on its instantaneous volume and its compliance; and the calculated pressure can be easily compared to the recorded data from the patient.

Regarding the impact of the protocol interventions, the model is consistent with the mechanisms described in Figure 1.

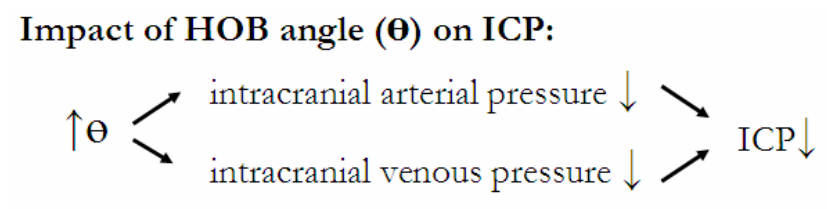

Impact of RR on ICP:

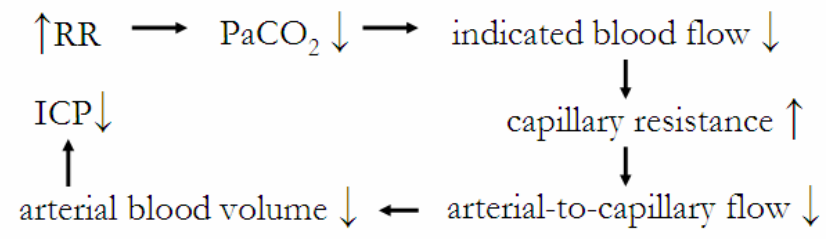

Figure 1. Impact of head of bed elevation and respiratory rate changes on intracranial pressure 
Changing the angle, $\theta$, of the HOB changes arterial pressure and ICP by an amount that is directly proportional to $\sin (\Delta \theta)$. The effects of changing minute ventilation are much more complex. Minute ventilation is the product of the respiratory frequency (or respiratory rate, RR) and tidal volume. As tidal volume was held constant during all the physiologic challenge periods, we varied $\mathrm{RR}$ to produce a change in minute ventilation. Changes in $\mathrm{RR}$ directly affect $\mathrm{PaCO}_{2}$, which is a vital part of the cerebral autoregulation mechanism - another complex feedback loop in our model. An increase in RR causes a decrease in cerebral blood flow and a subsequent increase in capillary resistance via affecting smooth muscle tone. The increase in capillary resistance decreases the arterial-to-capillary flow to match the indicated flow, and thus affects cerebral arterial blood volume.

The model was implemented in MATLAB Simulink® (The MathWorks, Inc., Natick, MA). The Appendix contains additional information about the ICP dynamic model.

\section{Parameter Estimation}

Parameter estimation refers to the mathematical process of adjusting the parameters of the model in order to achieve an objective, i.e. to minimize the error between the actual data and the data generated by the model. The primary inputs to the ICP dynamic model were the random changes to the $\mathrm{HOB}$ and minute ventilation specified by the physiologic challenge protocol. These changes entered the model as step functions at the times specified in the clinical annotations to the data. There were no other time-based inputs to the model; all other parameters were either initial values or constants. Although the protocol sessions provided multiple physiological signals for each subject, the only measurement used by the estimation process was the ICP signal, which was compared to the ICP computed by the model in order determine model fitness for specific sets of parameter values. 
Besides the state variables (volumes) and inputs (the timing of the physiologic challenge events), the other dynamic quantities in the model were the parameters being adjusted during the model identification process. These physiologic parameters were estimated for each subject based on the measured ICP response. The estimation was done by varying the parameters with the objective being to minimize the sum of squared differences between the ICP response calculated by the model and the actual ICP data, ignoring some outliers (for example, at the very beginning of a simulation run when the system of equations has sometimes not yet stabilized, or where the actual ICP data showed likely measurement discrepancies). MATLAB's lsqcurvefit nonlinear optimization algorithm was specified to run either until the change in the sum of the squared errors fell below a certain tolerance, or until a certain number of iterations had been completed. The algorithm required many simulations of the model to be run, each with slightly different parameter values. Since most model runs took a minute or longer to compute, the entire nonlinear optimization process often took one or more hours to complete for a given case (subject/session).

The initial parameter values were derived from the medical literature of past reported ICP computer models (14). The procedure for estimating parameter values that minimized the difference between the model-calculated ICP values over time and the actual ICP signal data (referred to as the "best fit") is shown in Figure 2. In each case, the nonlinear optimization algorithm was configured to vary between 4 to 8 parameters. The parameters were chosen from the following group based on sensitivity testing and their applicability to the challenges prescribed in the challenge protocol: autoregulation factor (smooth muscle compliance effect), basal cranial volume, CSF drainage rate, hematoma increase rate, $\Delta$ pressure time constant (a smoothing parameter associated with $\mathrm{HOB}$ elevation change), $\mathrm{ETCO}_{2}$ time constant 


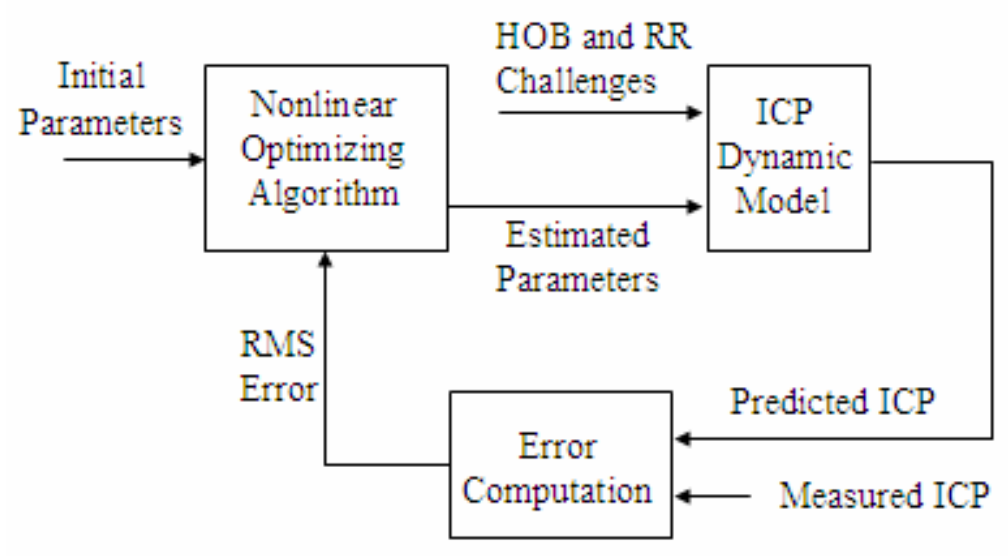

Figure 2. Parameter estimation process using an optimization algorithm to find the "best fit" parameter values.

(a smoothing parameter associated with RR changes), smooth muscle gain (a multiplicative factor related to the impact of smooth muscle tension), systemic venous pressure, "baseline" ICP, and the pressure volume index (PVI).

\section{Statistical Analysis: Prediction Assessment}

To present the results from computer-generated predictions and compare them to actual data, we chose to use mean absolute deviation (MAD) and mean absolute error (MAE). MAD describes the degree to which data in a sample varies from it mean. As indicated in Equation 1 MAD is the simple average of the individual absolute differences. Standard deviation, another widely used measure of variation, takes the root-mean-square of the differences. Similar to MAD, MAE, as indicated in Equation 2, is the average absolute difference between the predicted values and the actual values. Besides being conceptually simpler, MAD and MAE do not give more "weight" to large discrepancies. Note, however, that the parameter estimation process described earlier minimized the squared error as is typically done. 


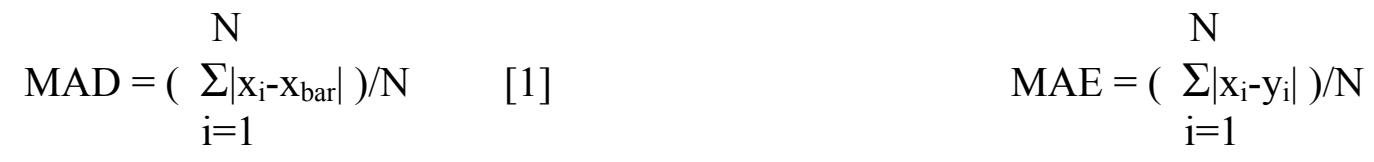

Figure 3 portrays the methods used to assess the prediction capability of the computer model. First, session-specific parameters were estimated using the process described earlier in

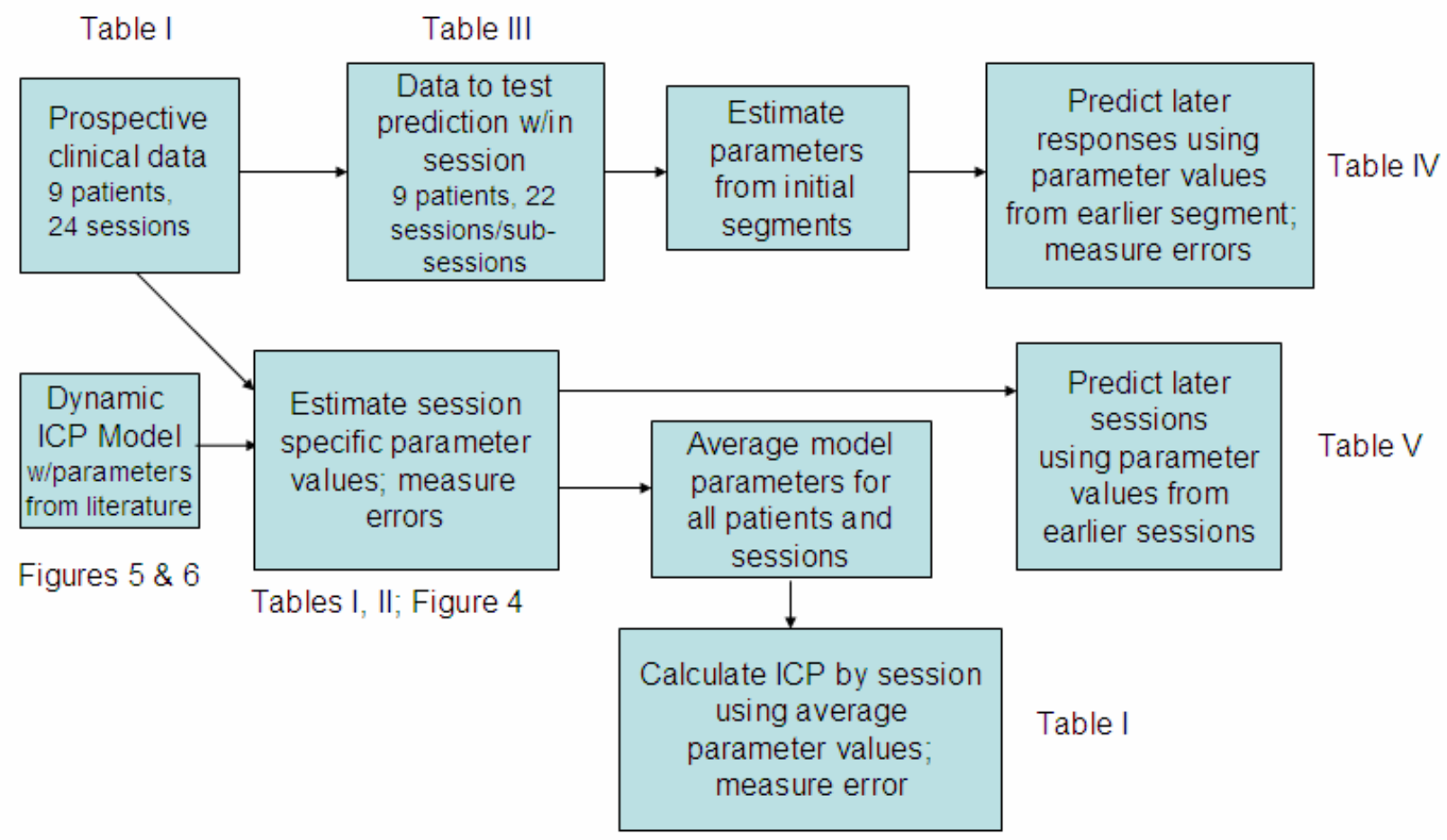

Figure 3. Overview of methodology to assess model prediction capability.

Figure 2, and the MAE for each session was computed to determine how accurately the model reproduced the actual ICP. The average parameter values for the model across subjects and sessions were determined by considering both the median and mean values for the parameter estimates from the parameter estimation runs for each session. The average parameter values were then used to estimate the ICP trajectory for each session, and the errors in these estimates 
were computed in order to determine the degree of improvement that was achieved by estimating session-specific parameters.

To determine how well the model was able to predict ICP response, two analyses were performed. First, the available subject data was reviewed to determine which sessions contained sufficient data to partition them into two segments, A and B, in order to conduct a "within" session analysis, such that Segment A could be used for estimation and Segment B for prediction. The criteria used for partitioning were that there were at least two protocol events in the session, with a sufficient stationary period between the events such that the events can be treated as separate occurrences (defined as $\geq 8$ minutes after the initial physiological challenge set). For sessions that could be partitioned accordingly, the best fit model parameters for Segment A were estimated, the resulting session/segment-specific model was used to predict the ICP responses in Segment B, and the prediction MAE was computed.

The second prediction analysis was a "between" session analysis for subjects with multiple sessions. This analysis used the session-specific parameter values from one or more early sessions to predict the ICP responses in later sessions and the MAEs were computed for these predictions. Parameters from multiple sessions were aggregated by taking their simple mean.

\section{Results}

We studied 9 subjects with severe TBI undergoing ICP monitoring ( $7 \mathrm{M} / 2 \mathrm{~F}$, age range 3 -17 years $)$

Table 1 shows specific information regarding each session, including its length, the various protocol events that occurred, the mean ICP, and the ICP MAD. Also shown is the error 
Table 1. Results of parameter estimation process for average parameter values and for sessionspecific parameter values.

\begin{tabular}{|c|c|c|c|c|c|c|c|c|c|c|}
\hline \multirow[b]{2}{*}{ \# } & \multirow[b]{2}{*}{$\begin{array}{l}\text { Subje } \\
\text { ct }\end{array}$} & \multirow[b]{2}{*}{ Session } & \multirow[b]{2}{*}{$\begin{array}{l}\text { Length } \\
\text { min }\end{array}$} & \multirow[b]{2}{*}{ Challenges } & \multicolumn{2}{|c|}{$\begin{array}{l}\text { Actual ICP Values } \\
(\mathrm{mmHg})\end{array}$} & \multicolumn{2}{|c|}{$\begin{array}{l}\text { Model Error } \\
\text { w/avg. parameter } \\
\text { values (mmHg) }\end{array}$} & \multicolumn{2}{|c|}{$\begin{array}{l}\text { Model Error } \\
\text { w/individually fit } \\
\text { parameter values } \\
(\mathrm{mmHg})\end{array}$} \\
\hline & & & & & $\begin{array}{l}\text { Mean } \\
\text { ICP }\end{array}$ & MAD & MAE & $\begin{array}{l}\text { Ratio } \\
\text { MAE / } \\
\text { MAD }\end{array}$ & MAE & $\begin{array}{l}\text { Ratio } \\
\text { MAE/ } \\
\text { MAD }\end{array}$ \\
\hline 1 & P004 & $\mathrm{S} 1$ & 12 & $1 \mathrm{HOB}$ & 7.30 & 1.25 & 13.2 & 10.6 & 0.92 & .73 \\
\hline 2 & & S3 & 18 & $1 \mathrm{HOB}$ & 11.61 & 4.87 & 13.2 & 2.71 & 0.89 & .18 \\
\hline 3 & & S4 & 45 & $1 \mathrm{HOB}, 3 \mathrm{RR}$ & 13.09 & 4.02 & 4.61 & 1.15 & 1.50 & .37 \\
\hline \multirow[t]{2}{*}{4} & & S5 & 68 & $3 \mathrm{HOB}, 3 \mathrm{RR}$ & 19.35 & 3.86 & 9.27 & 2.40 & 2.81 & .73 \\
\hline & & & & Weighted Avg. & 15.4 & 3.82 & 8.36 & 2.26 & 2.01 & .53 \\
\hline 5 & P006 & S1 & 55 & $4 \mathrm{HOB}$ & 5.90 & 1.38 & 16.7 & 12.1 & 0.69 & .50 \\
\hline 6 & & S4 & 65 & $2 \mathrm{RR}$ & 6.89 & 2.26 & 10.1 & 4.47 & 0.80 & .36 \\
\hline 7 & & S7 & 110 & $5 \mathrm{HOB}, 4 \mathrm{RR}$ & 11.80 & 3.37 & 3.26 & .97 & 2.29 & .68 \\
\hline 8 & & S8 & 38 & $1 \mathrm{HOB}$ & 14.66 & 7.57 & 3.39 & .45 & 1.89 & .24 \\
\hline \multirow[t]{2}{*}{9} & & S9 & 55 & $5 \mathrm{HOB}$ & 6.46 & 2.34 & 7.14 & 3.05 & 0.50 & .21 \\
\hline & & & & Weighted Avg. & 9.23 & 3.13 & 7.60 & 2.43 & 1.36 & .43 \\
\hline 10 & P007 & S1 & 45 & $5 \mathrm{HOB}$ & 13.50 & 5.49 & 7.27 & 1.32 & 4.96 & .90 \\
\hline 11 & & S3 & 70 & $6 \mathrm{HOB}$ & 17.28 & 3.55 & 6.68 & 1.88 & 3.04 & .86 \\
\hline \multirow[t]{2}{*}{12} & & S8 & 60 & $5 \mathrm{HOB}$ & 16.99 & 1.90 & 3.39 & 1.78 & 2.74 & 1.44 \\
\hline & & & & Weighted Avg. & 16.2 & 3.48 & 5.70 & 1.64 & 3.43 & .99 \\
\hline 13 & P201 & $\mathrm{S} 1$ & 125 & $3 \mathrm{HOB}$ & 22.83 & 1.37 & 12.3 & 8.99 & 2.41 & 1.76 \\
\hline 14 & & $\mathrm{~S} 2$ & 50 & $3 \mathrm{HOB}$ & 18.25 & 2.16 & 7.76 & 3.59 & 1.21 & .56 \\
\hline 15 & & S3 & 52 & $2 \mathrm{RR}$ & 18.80 & 2.78 & 5.90 & 2.12 & 2.05 & .74 \\
\hline \multirow[t]{2}{*}{16} & & S5 & 77 & $2 \mathrm{HOB}, 1 \mathrm{RR}$ & 14.25 & 1.72 & 4.04 & 2.35 & 1.54 & .89 \\
\hline & & & & Weighted Avg. & 19.2 & 1.83 & 8.35 & 4.57 & 1.93 & 1.06 \\
\hline 17 & P202 & S1 & 90 & $2 \mathrm{HOB}, 5 \mathrm{RR}$ & 16.53 & 1.53 & 3.23 & 2.11 & 1.00 & .65 \\
\hline 18 & & S2 & 36 & $2 \mathrm{HOB}$ & 16.85 & 0.93 & 5.56 & 5.98 & 1.12 & 1.20 \\
\hline 19 & & S3 & 70 & $1 \mathrm{RR}$ & 19.35 & 1.35 & 8.89 & 6.59 & 0.63 & .46 \\
\hline \multirow[t]{2}{*}{20} & & S4 & 60 & $2 \mathrm{HOB}, 2 \mathrm{RR}$ & 21.10 & 5.78 & 11.42 & 1.98 & 1.73 & .30 \\
\hline & & & & Weighted Avg. & 18.4 & 2.39 & 7.02 & 2.94 & 1.08 & .45 \\
\hline 21 & P204 & S2 & 130 & $4 \mathrm{HOB}, 4 \mathrm{RR}$ & 15.19 & 3.22 & 8.07 & 2.51 & 1.67 & .52 \\
\hline 21 & $\mathrm{P} 205$ & S4 & 34 & $2 \mathrm{HOB}$ & 10.31 & 3.55 & 4.49 & 1.26 & 1.05 & .30 \\
\hline 23 & P206 & S1 & 58 & $5 \mathrm{HOB}$ & 11.82 & 1.94 & 6.02 & 3.10 & 1.01 & 52 \\
\hline 24 & P207 & S1 & 70 & $8 \mathrm{HOB}$ & 13.65 & 4.19 & 4.62 & 1.10 & 4.02 & .96 \\
\hline & & & Overa & Weighted Avg. & 15.1 & 2.87 & 7.30 & 2.55 & 1.86 & .65 \\
\hline
\end{tabular}

in model-calculated ICP for two cases: (1) using the average parameter values and (2) using the session-specific parameter values. Summary rows pertaining to multiple sessions were 
computed as weighted means based on session length. Table 1 indicates that using average parameter values does not provide accurate predictions, with an average MAE in excess of 7 $\mathrm{mmHg}$. Since the average MAD for these sessions was about $3 \mathrm{mmHg}$, a naïve model which assumed that ICP would simply remain constant at its mean value for the entire session would be considerably more accurate. The results when using patient-specific parameter values were much better, with a mean MAE of $1.86 \mathrm{mmHg}$. The ratio of MAE to MAD for these models is less than one on average for 8 of 9 subjects, although 3 out of 24 sessions had an MAE/MAD $>1$. On the other hand, the weighted average MAE/MAD for six of the nine subjects was at or below 0.5 .

Figure 4 provides a thumbnail picture for each session, showing the protocol interventions, and the model results using the session-specific parameters. The modeled response is very close to the actual response in most cases. Some notable exceptions were found in: subject Nos. $10,11 \& 12$, where there was a mechanical artifact in the actual ICP signal; subject No. 10 where the parameter estimation process found parameters that effectively neutralized the "normal" response logic, but the model was not capable [by design] of being calibrated to produce the opposite response; subject No. 3 where the predicted response at the end of the session was much greater than the actual response because the parameters were chosen to match an early and very pronounced response to a similar change in HOB; and, subject No. 24 where the predicted ICP variations were similar to actual variations in some respects, but not in others and were found to be a result of external stimulus from the subject's parents.

Table 2 provides additional information regarding model fitness by patient, by type of challenge during the session, by the number of challenges, by the length of the session, and by the mean ICP for the session. This table clearly shows the two patients whose responses were difficult to capture in the model, and also that the model error for the other seven patients was 
Figure 4. Thumbnail images of each session and the predicted ICP using individually fit parameter values listed in Table 1. The individual plot numbers correspond to those in Table 1. The recorded ICP waveform is the green jagged trace. The modeled ICP is the non-jagged blue trace. The red and black traces at the bottom show changes in the HOB and ventilation rate, respectively.
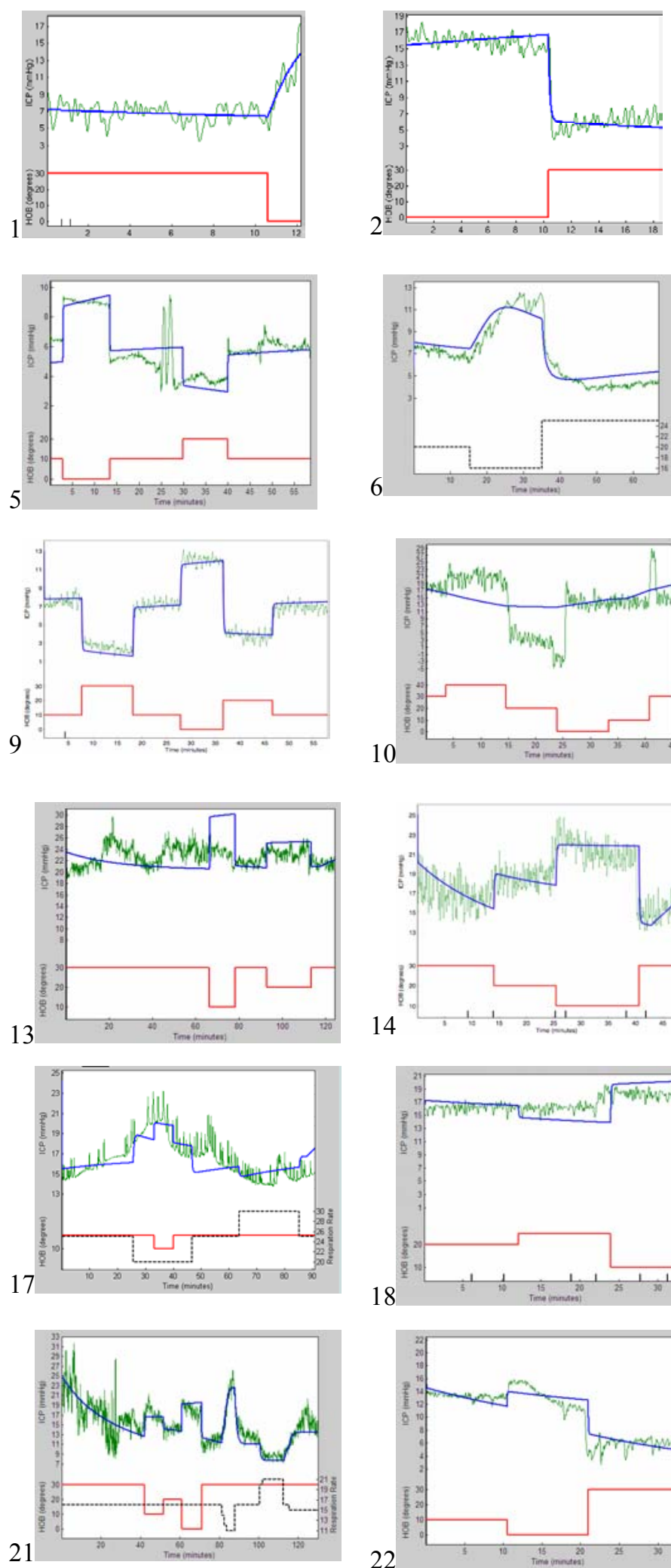
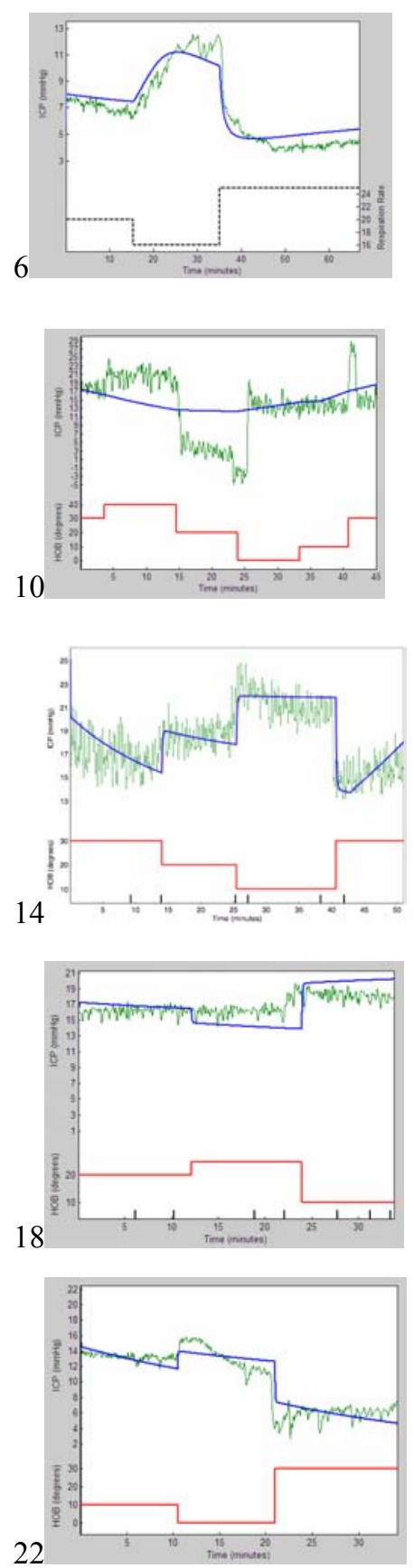
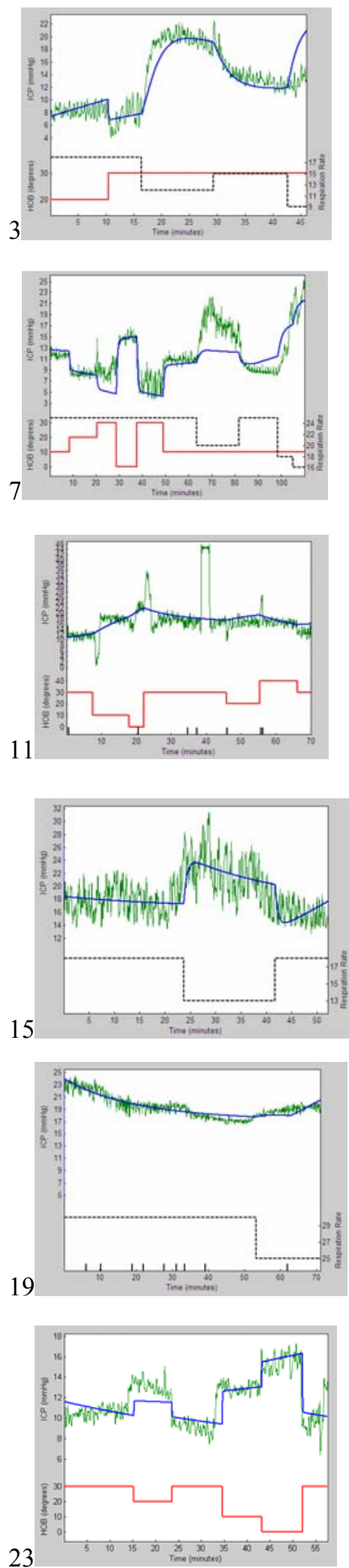
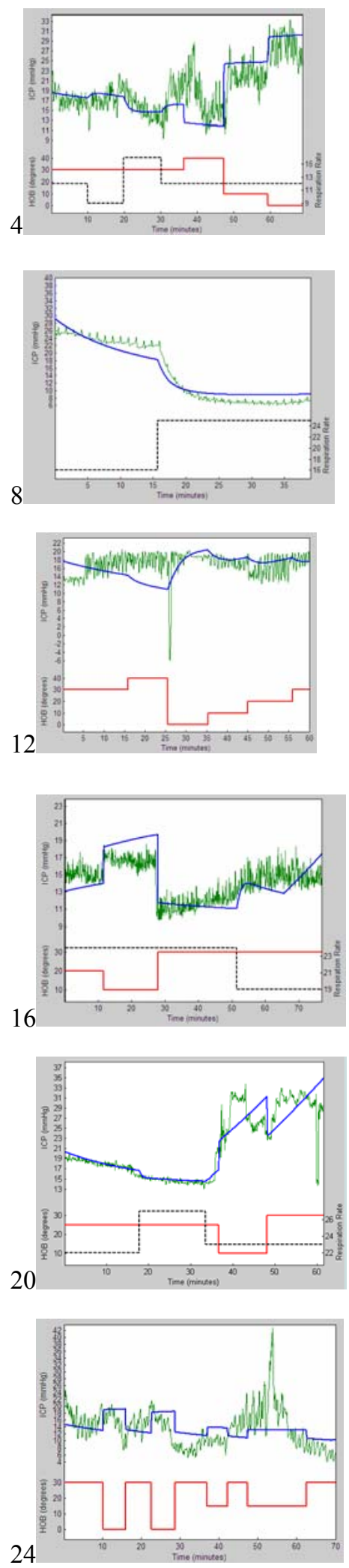
Table 2. Mean model error by subject and for various subcategories

\begin{tabular}{|c|c|c|c|c|c|c|c|c|c||c|}
\hline & P004 & P006 & P007 & P201 & P202 & P204 & P205 & P206 & P207 & All \\
\hline $\begin{array}{c}\text { Mean } \\
\text { MAE }\end{array}$ & 2.01 & 1.36 & 3.43 & 1.93 & 1.08 & 1.67 & 1.05 & 1.01 & 4.02 & 1.86 \\
\hline N & 4 & 5 & 3 & 4 & 4 & 1 & 1 & 1 & 1 & 24 \\
\hline
\end{tabular}

\begin{tabular}{|c|c|c|c|c|c|}
\hline & $\begin{array}{l}\text { HOB Only } \\
\text { Challenges }\end{array}$ & $\begin{array}{c}\text { RR Only } \\
\text { Challenges }\end{array}$ & $\begin{array}{c}\text { HOB and } \\
\text { RR }\end{array}$ & $\begin{array}{c}\leq \mathbf{3} \\
\text { Challenges }\end{array}$ & $\begin{array}{c}\geq 4 \\
\text { Challenges }\end{array}$ \\
\hline $\begin{array}{l}\text { Mean } \\
\text { MAE }\end{array}$ & 1.96 & 1.16 & 2.10 & 1.43 & 2.29 \\
\hline $\mathbf{N}$ & 14 & 3 & 7 & 10 & 14 \\
\hline
\end{tabular}

\begin{tabular}{|c|c|c|c|c|}
\hline & \multicolumn{4}{|c|}{ Length of Session (minutes) } \\
\hline & $<=40$ & $41-60$ & $61-80$ & $>80$ \\
\hline $\begin{array}{c}\text { Mean } \\
\text { MAE }\end{array}$ & 1.18 & 1.82 & 2.14 & 2.21 \\
\hline N & 5 & 9 & 6 & 4 \\
\hline
\end{tabular}

\begin{tabular}{|c|c|c|}
\hline \multicolumn{3}{|c|}{ Mean ICP for Session (mmHg) } \\
\hline $\begin{array}{c}\text { Low } \\
(<12)\end{array}$ & $\begin{array}{c}\text { Medium } \\
(12-18)\end{array}$ & $\begin{array}{c}\text { High } \\
(>18)\end{array}$ \\
\hline 1.00 & 2.36 & 1.81 \\
\hline 8 & 10 & 6 \\
\hline
\end{tabular}

considerably smaller. Although the grouping of RR-only sessions indicated much lower error, there were only three sessions in this group, none of which involved the two "problematic" patients. As might be expected, MAE was larger for sessions that were longer or contained more challenges. MAE was higher when the mean ICP for the session was moderate rather than being either low or high.

Table 3 describes the 22 situations that were amenable to predicting the response within a given session. Of the 24 sessions included in this study, 19 contained sufficient data to use an early segment of the session (the parameter estimation segment, A) to estimate the ICP response to challenges in a later segment of the session (the predicted segment, B). Three sessions could be further subdivided into an HOB segment and an RR segment, both of which contained sufficient data to be able to conduct a within-segment prediction test for the HOB response 
separately from the RR response. Thus there were 22 segments for testing within-session

prediction. The average ICP in Segment A and Segment B were nearly equal $(\sim 16 \mathrm{mmHg})$. The overall MAD in both segments was also nearly the same $(\sim 2.5 \mathrm{mmHg})$. MAE and the ratio

Table 3. Results of within-session intracranial pressure prediction - by estimating model parameters from the patient response(s) during an initial segment of the session; then predicting the subsequent segment.

\begin{tabular}{|c|c|c|c|c|c|c|c|c|c|c|c|c|}
\hline \multirow[b]{2}{*}{$\#$} & \multirow[b]{2}{*}{ Subject } & \multirow[b]{2}{*}{$\begin{array}{l}\text { Session// } \\
\text { Subsession }\end{array}$} & \multicolumn{5}{|c|}{ Initial Segment (A) } & \multicolumn{5}{|c|}{ Predicted Segment (B) } \\
\hline & & & $\begin{array}{l}\text { Len } \\
\text { gth } \\
\text { min }\end{array}$ & $\begin{array}{l}\text { Mean } \\
\text { ICP } \\
\text { mmHg }\end{array}$ & $\begin{array}{l}\text { MAD } \\
\text { mmHg }\end{array}$ & $\begin{array}{l}\text { Best fit } \\
\text { ICP } \\
\text { MAE } \\
\text { mmHG }\end{array}$ & $\begin{array}{l}\text { Ratio } \\
\text { MAE/ } \\
\text { MAD }\end{array}$ & $\begin{array}{l}\text { Len } \\
\text { gth } \\
\text { min }\end{array}$ & $\begin{array}{l}\text { Mean } \\
\text { ICP } \\
\text { mmHg }\end{array}$ & $\begin{array}{l}\text { MAD } \\
\text { mmHg }\end{array}$ & $\begin{array}{l}\text { Pred. } \\
\text { ICP } \\
\text { MAE } \\
\text { mmHG }\end{array}$ & $\begin{array}{l}\text { Ratio } \\
\text { MAE/ } \\
\text { MAD }\end{array}$ \\
\hline 1 & P004 & S4 & 35 & 13.1 & 5.01 & 1.02 & .20 & 10 & 12.9 & .76 & 3.27 & 4.30 \\
\hline 2 & & S5 RR & 35 & 17.3 & 1.41 & 1.29 & .91 & 8 & 14.7 & 2.03 & 3.22 & 1.59 \\
\hline \multirow[t]{2}{*}{3} & & S4 HOB & 20 & 18.8 & 3.34 & 2.52 & .75 & 16 & 25.6 & 3.22 & 3.61 & 1.12 \\
\hline & & Average & & 15.9 & 3.47 & 1.48 & .43 & & 16.6 & 1.77 & 3.34 & 1.88 \\
\hline 4 & P006 & S1 & 20 & 7.40 & 1.68 & .57 & .34 & 35 & 5.13 & 1.02 & .66 & .65 \\
\hline 5 & & S4 & 25 & 7.77 & .97 & .29 & .30 & 40 & 6.36 & 2.77 & 1.22 & .44 \\
\hline 6 & & S7 HOB & 33 & 10.1 & 1.91 & 1.00 & .52 & 22 & 9.64 & 2.98 & 1.27 & .42 \\
\hline 7 & & S7 RR & 35 & 13.8 & 3.44 & 2.38 & .69 & 20 & 13.3 & 4.93 & 3.96 & .80 \\
\hline \multirow[t]{2}{*}{8} & & S9 & 24 & 5.1 & 2.35 & .32 & .14 & 31 & 7.33 & 2.38 & .98 & .41 \\
\hline & & Average & & 9.35 & 2.17 & 1.04 & .48 & & 8.91 & 3.05 & 1.81 & .59 \\
\hline 9 & P007 & S1 & 30 & 12.8 & 7.39 & 6.04 & .82 & 15 & 14.9 & 2.05 & 11.2 & 5.47 \\
\hline 10 & & S3 & 30 & 16.4 & 4.02 & 2.47 & .61 & 40 & 18.0 & 3.50 & 5.26 & 1.50 \\
\hline \multirow[t]{2}{*}{11} & & S8 & 30 & 16.6 & 2.24 & 2.81 & 1.25 & 30 & 17.4 & 1.53 & 8.24 & 5.37 \\
\hline & & Average & & 15.3 & 4.55 & 3.77 & .83 & & 16.7 & 2.36 & 8.23 & 3.49 \\
\hline 12 & P201 & $\mathrm{S} 1$ & 85 & 22.9 & 1.51 & 4.79 & 3.17 & 40 & 22.7 & 1.05 & 3.28 & 3.13 \\
\hline 13 & & S2 & 30 & 18.4 & 1.77 & .99 & .56 & 20 & 18.0 & 2.73 & 2.90 & 1.07 \\
\hline 14 & & S3 & 30 & 19.1 & 2.69 & 2.07 & .77 & 22 & 18.4 & 2.87 & 3.37 & 1.17 \\
\hline \multirow[t]{2}{*}{15} & & S5 & 20 & 15.9 & .96 & .57 & .59 & 57 & 13.7 & 1.71 & 2.80 & 1.64 \\
\hline & & Average & & 20.5 & 1.71 & 3.09 & 1.81 & & 20.0 & 1.77 & 3.17 & 1.79 \\
\hline 16 & P202 & S1 & 36 & 17.1 & 1.69 & .41 & .24 & 54 & 16.1 & 1.41 & 2.19 & 1.55 \\
\hline \multirow[t]{2}{*}{17} & & S4 & 42 & 17.8 & 2.87 & 1.29 & .45 & 18 & 28.5 & 2.76 & 12.0 & 4.37 \\
\hline & & Average & & 17.5 & 2.33 & 0.88 & .38 & & 22.8 & 2.14 & 7.47 & 3.50 \\
\hline 18 & P204 & S2 HOB & 57 & 17.1 & 2.73 & 2.80 & 1.03 & 23 & 14.8 & 2.85 & 9.16 & 3.21 \\
\hline \multirow[t]{2}{*}{19} & & S2 RR & 20 & 15.4 & 3.37 & 1.02 & .30 & 35 & 11.9 & 2.54 & 1.28 & .51 \\
\hline & & Average & & 16.6 & 2.90 & 2.34 & .81 & & 14.0 & 2.77 & 7.11 & 2.57 \\
\hline 20 & P205 & S4 & 16 & 13.7 & .68 & .49 & .76 & 18 & 7.31 & 2.20 & 3.14 & 1.43 \\
\hline 21 & P206 & S1 & 30 & 11.0 & 1.31 & .81 & .62 & 23 & 12.7 & 2.07 & 3.32 & 1.61 \\
\hline 22 & P207 & S1 & 32 & 14.6 & 3.12 & 2.94 & .94 & 38 & 12.8 & 4.70 & 4.83 & 1.03 \\
\hline \multicolumn{2}{|c|}{ Overall } & Average & & 15.6 & 2.58 & 2.11 & .82 & & 15.8 & 2.40 & 4.56 & 1.90 \\
\hline
\end{tabular}

MAE/MAD are shown for both the estimation (or training) segment and the predicted segment.

The weighted average MAE for the predicted ICP in Segment B was $4.56 \mathrm{mmHg}$, despite the fact that the weighted average MAE for training segment was $2.11 \mathrm{mmHg}$, which is less than the 
weighted average MAD of $2.58 \mathrm{mmHg}$. The high weighted average prediction MAE was influenced by four segments with MAE $>8 \mathrm{mmHg}$. Offsetting these high values was five segments with $\mathrm{MAE} \sim 1 \mathrm{mmHg}$, and the MAE for most of the remaining 13 segments was between 2 and $4 \mathrm{mmHg}$.

Table 4 shows the results of using the estimated parameters from one or more prior

Table 4. Results of using parameters estimated from prior sessions to estimate intracranial pressure response in subsequent sessions.

\begin{tabular}{|c|c|c|c|c|c|c|c|c|}
\hline \multirow[t]{2}{*}{ \# } & \multirow{2}{*}{$\begin{array}{l}\text { Subje } \\
\text { ct }\end{array}$} & & \multicolumn{6}{|c|}{ Predicted Session } \\
\hline & & $\begin{array}{l}\text { Parameters from } \\
\text { Session(s) }\end{array}$ & $\begin{array}{l}\text { Session } \\
\text { No. }\end{array}$ & $\begin{array}{l}\text { Length } \\
\text { min }\end{array}$ & $\begin{array}{l}\text { Mean } \\
\text { ICP } \\
\text { mmHg }\end{array}$ & $\begin{array}{l}\text { MAD } \\
\text { ICP } \\
\text { mmHg }\end{array}$ & $\begin{array}{l}\text { MAE } \\
\text { Predicted } \\
\text { ICP } \\
\text { mmHG } \\
\end{array}$ & $\begin{array}{l}\text { Ratio } \\
\text { MAE/MAD }\end{array}$ \\
\hline 1 & \multirow[t]{3}{*}{ P004 } & S1 & S3 & 18 & 11.6 & 4.87 & 2.95 & .6 \\
\hline $\begin{array}{l}2 \\
3\end{array}$ & & $\begin{array}{l}\text { S1 } \\
\text { S1\&S3 }\end{array}$ & S4 & 45 & 13.1 & 4.02 & $\begin{array}{l}5.37 \\
6.91\end{array}$ & $\begin{array}{l}1.34 \\
1.72\end{array}$ \\
\hline $\begin{array}{l}4 \\
5 \\
6 \\
\end{array}$ & & $\begin{array}{l}\text { S1 } \\
\text { S1\&S3 } \\
\text { S1\&S3\&S4 } \\
\end{array}$ & S5 & 68 & 19.4 & 3.86 & $\begin{array}{l}7.81 \\
9.68 \\
8.36 \\
\end{array}$ & $\begin{array}{l}2.02 \\
2.51 \\
2.17 \\
\end{array}$ \\
\hline 7 & \multirow[t]{4}{*}{ P006 } & $\mathrm{S} 1$ & S4 & 65 & 6.89 & 2.26 & 5.10 & 2.25 \\
\hline $\begin{array}{l}8 \\
9\end{array}$ & & $\begin{array}{l}\text { S1 } \\
\text { S1\&S4 }\end{array}$ & S7 & 110 & 11.8 & 3.37 & $\begin{array}{l}10.53 \\
8.90\end{array}$ & $\begin{array}{l}3.13 \\
2.64\end{array}$ \\
\hline $\begin{array}{l}10 \\
11 \\
12 \\
\end{array}$ & & $\begin{array}{l}\text { S1 } \\
\text { S1\&S4 } \\
\text { S1\&S4\&S7 }\end{array}$ & S8 & 38 & 1456 & 7.57 & $\begin{array}{l}13.20 \\
10.46 \\
8.07 \\
\end{array}$ & $\begin{array}{l}1.74 \\
1.38 \\
1.07 \\
\end{array}$ \\
\hline $\begin{array}{l}13 \\
14 \\
15 \\
16\end{array}$ & & $\begin{array}{l}\text { S1 } \\
\text { S1\&S4 } \\
\text { S1\&S4\&S7 } \\
\text { S1\&S4\&S7\&S8 }\end{array}$ & S9 & 55 & 6.46 & 2.34 & $\begin{array}{l}5.54 \\
3.87 \\
2.01 \\
.90 \\
\end{array}$ & $\begin{array}{l}2.37 \\
1.66 \\
.86 \\
.39 \\
\end{array}$ \\
\hline 17 & \multirow[t]{2}{*}{ P007 } & S1 & S3 & 70 & 17.3 & 3.55 & 6.02 & 1.70 \\
\hline $\begin{array}{l}18 \\
19 \\
\end{array}$ & & $\begin{array}{l}\mathrm{S} 1 \\
\mathrm{~S} 1+\mathrm{S} 3 \\
\end{array}$ & S8 & 60 & 17.0 & 1.90 & \begin{tabular}{|l|}
5.43 \\
4.88 \\
\end{tabular} & $\begin{array}{l}2.86 \\
2.57\end{array}$ \\
\hline 20 & \multirow[t]{3}{*}{ P201 } & S1 & S2 & 50 & 18.3 & 2.16 & 4.78 & 2.21 \\
\hline $\begin{array}{l}21 \\
22 \\
\end{array}$ & & $\begin{array}{l}\text { S1 } \\
\text { S1\&S2 }\end{array}$ & S3 & 52 & 18.8 & 2.78 & $\begin{array}{l}11.37 \\
12.21 \\
\end{array}$ & $\begin{array}{l}4.09 \\
4.40 \\
\end{array}$ \\
\hline $\begin{array}{l}23 \\
24 \\
25 \\
\end{array}$ & & $\begin{array}{l}\text { S1 } \\
\text { S1\&S2 } \\
\text { S1\&S2\&S3 }\end{array}$ & S5 & 77 & 4.25 & 1.72 & $\begin{array}{l}5.72 \\
3.89 \\
3.72 \\
\end{array}$ & $\begin{array}{l}3.33 \\
2.26 \\
2.17 \\
\end{array}$ \\
\hline 26 & \multirow[t]{4}{*}{ P202 } & S1 & S2 & 36 & 16.9 & .93 & 3.20 & 3.45 \\
\hline $\begin{array}{l}27 \\
28\end{array}$ & & $\begin{array}{l}\mathrm{S} 1 \\
\mathrm{~S} 1 \& \mathrm{~S} 2\end{array}$ & S3 & 70 & 19.4 & 1.35 & $\begin{array}{l}6.31 \\
7.04\end{array}$ & $\begin{array}{l}4.66 \\
5.12\end{array}$ \\
\hline $\begin{array}{l}29 \\
30 \\
31 \\
\end{array}$ & & $\begin{array}{l}\text { S1 } \\
\text { S1\&S2 } \\
\text { S1\&S2\&S3 }\end{array}$ & S4 & 69 & 21.2 & 5.78 & $\begin{array}{l}9.12 \\
9.92 \\
5.78 \\
\end{array}$ & $\begin{array}{l}1.58 \\
1.72 \\
1.00 \\
\end{array}$ \\
\hline & & Weighted Avg. & & & 14.3 & 3.10 & 6.74 & 2.23 \\
\hline
\end{tabular}


sessions to predict the patient's ICP response during subsequent sessions. A total of 31 cases were tested. The average MAE for this test was $6.74 \mathrm{mmHg}$. For five of the 10 predicted sessions that were estimated by more than one parameter set, the prediction error was reduced when parameter estimates from multiple sessions were incorporated. However, for four other sessions, prediction error increased when parameter estimates from multiple sessions were aggregated.

\section{Discussion}

Our main findings were that a protocol for collecting physiologic challenge data in subjects with severe TBI is feasible and without undue risk. Our in silico dynamic ICP model was able to consistently and accurately reproduce the subject's ICP response to changes in RR and HOB, with a few noted exceptions. Finally, we demonstrated modest success at predicting future ICP changes within a session and, to a lesser extent, between sessions.

The potential advantages for such an approach are many. Essentially all therapies for increased ICP have risks as well as benefits, and some of the risks are substantial including cerebral ischemia and worsening ICP. Therefore, the ability to test a specific subject's best response to different therapies before they are administered and determine which would be optimal (i.e. best therapeutic response with lowest adverse effect) would be ideal.

Over the past 30 years, a variety of computer models for calculating ICP dynamics have been published in the biomedical engineering literature $(15,16)$. These models use differential equations to calculate the pressure at different points within the system, taking into account the blood vessel and anatomic compartment volumes and compliances. Although interesting mathematical results and pathophysiologic insights have been gained from these models, their impact on clinical practice has been limited. Reasons for this limited impact may include the 
complexity of the models and the limited range of bedside in vivo clinical scenarios represented. Researchers have attempted to address these limitations by simplifying their models (17) and by adding clinically meaningful functionality. Some parameter estimates derived from the laboratory data and/or clinical data have been reported, but much of the necessary data remains difficult to obtain. Models have been calibrated to fit data recorded for specific patients $(7,8$, $11-13,17-21)$ and excellent results have been reported in some cases $(8,21)$. However, to our knowledge actual prediction of patient-specific ICP response to therapies or other interventions has not been reported. Thus, we suggest that use of an approach similar to ours that incorporates detailed and lengthy data recordings plus clinically annotated information (e.g. including the exact timing for medications, CSF drainage, ventilator adjustments, etc.) will be required for any ICP model to be clinically useful, and will most certainly be needed if models are to be used to predict response to therapy.

The model used in the present research is similar in many ways to previously reported dynamic ICP models by our research group in that it considers the cranial vault to contain the brain parenchyma plus several fluid "compartments" that together are constrained not to exceed the total cranial volume (11-13). The fluid compartments include the arterial blood volume, capillary blood volume, venous blood volume, CSF volume, the brain volume, and "other" volume that may or may not be present in a particular patient (e.g. epidural or subdural hematoma, intraparenchymal hemorrhage). The brain volume can be either constant or variable, based on the presence and degree of cerebral edema.

Consistent with prior investigators $(15,17)$, autoregulation is modeled as a feedback loop that causes the cerebral vasculature to dilate or constrict, taking into account control limits that are non-linear and asymmetric. The control logic in our model acts only on the flow of blood from the arterial compartment to the capillary bed. The control logic is proportional and has 
enough "gain" that it can easily maintain the required flow under normal conditions. However, if the venous or arterial volumes are severely reduced, as is often the case with severe TBI, the associated nonlinear increases in resistance can "overwhelm" the model's simplified control logic in an unrealistic fashion.

The main difference between our ICP dynamic model and other models reported in the literature is that the state variables are modeled as volumes rather than pressures, and the fluid flows into and out of each compartment are clearly identified and represented. This approach is more intuitive, and may facilitate the representation of in vivo pathophysiologic processes. Blood pressures are computed from the volumes of the blood compartments and their associated compliances. ICP is computed using the total intracranial volume and the pressure volume index (11-13).

Our model incorporates logic associated with severe TBI pathophysiology, including the "other" volume mentioned above, ongoing intracranial bleeding, and focal or generalized cerebral edema. The model also incorporates common therapeutic interventions such as elevation of the HOB and changing the minute ventilation to induce mild hyperventilation (decreasing $\mathrm{PaCO}_{2}$ to $33-35 \mathrm{mmHg}$ ). We have previously shown that the behavior of our model was qualitatively correct $(11,12)$, and we were able to manually calibrate the model so that it replicated retrospective clinical data from two prior subject-specific cases (13). Preliminary parameter estimation results were reported in (12). Further details regarding the model are provided in the Appendix.

\section{Study Limitations}

The ICP dynamic model employed in this study may be too simplified to be able to accomplish the task of prediction of future therapeutic response. More complex models have 
been reported in the literature, and such models have been shown to be able to match clinical data even better than the results shown in Figure 4. Ursino et al (8) showed model-calculated ICP dynamics that are nearly identical to the data. Still, the results shown in Figure 4 indicate that our model is capable of repeatedly generating ICP responses very similar to those seen in the actual clinical data.

Additionally, we may not have collected all pertinent clinically annotated data nor accurately incorporated it into the model. Clearly, in a clinical situation all factors that influence ICP cannot be controlled (e.g. bedside visitors to the ICU, coughing, administration of scheduled medications, etc.). Incorporating additional data about cerebral edema or intra- or extracranial hematoma or hemorrhage from computed tomograpghy or magnetic resonance imaging scans may also be of value. And using data from other organ systems (e.g. blood pressure, heart rate, arterial oxygen saturation, etc.) and other methods for neuromonitoring (e.g. near infrared spectroscopy, brain tissue oxygenation, etc.) may also improve either the model or the predictive capabilities. However, while deleting data that does not improve the model may improve the overall prediction accuracy, if there is any hope of simulating a real clinical scenario this type of "unclean" data needs to be incorporated into the model

\section{Conclusions}

The complexity of the underlying physiologic processes and the dynamic characteristics of the ICU environment make it difficult for a computer model to reliably predict ICP responses. Nevertheless, we have demonstrated a novel method for data collection, a new dynamic ICP model, and an initial attempt to use the model to predict a subject's response to therapy. We suggest that this area of research should be explored in the future with an emphasis on building 
models that more completely reflect the underlying physiology and that incorporate even finer and more granular clinical data.

\section{Acknowledgements}

We gratefully acknowledge financial support from the Thrasher Research Fund that made this research possible; and the support, encouragement, and assistance from James McNames, Associate Professor of Electrical and Computer Engineering, and Director of the Biological Signal Processing Laboratory at Portland State University. 


\section{References}

1. Teasdale G, Jennett B: Assessment of coma and impaired consciousness. A practical scale. Lancet 1974;2:81-84

2. White J, Dalton H: Pediatric Trauma: Post-Injury Care in the Pediatric Intensive Care Unit. Crit Care Med 2002;30:S478-S488

3. Adelson PD, Bratton SL, Carney NA, Chesnut RM, du Coudray HE, Goldstein B, et al.: Guidelines for the acute medical management of severe traumatic brain injury in infants, children, and adolescents. Chapter 6. Threshold for treatment of intracranial hypertension. Pediatr Crit Care Med 2003;4:S25-27

4. Adelson PD, Bratton SL, Carney NA, Chesnut RM, du Coudray HE, Goldstein B, et al.: Guidelines for the acute medical management of severe traumatic brain injury in infants, children, and adolescents. Chapter 1: Introduction. Pediatr Crit Care Med 2003;4:S2-4

5. Goldstein B, Powers KS: Head trauma in children. Pediatr Rev 1994;15:213-219; quiz 219

6. Rosner M. Pathophysiology and management of increased intracranial pressure. In: Andrew BT, editor. Neurosurgical Intensive Care. New York: McGraw-Hill, Inc.; 1993. p. $57-112$

7. Hu X, Nenov V, Bergsneider M, Glenn TC, Vespa P, Martin N: Estimation of hidden state variables of the intracranial system using constrained nonlinear Kalman filters. IEEE Transactions on Biomedical Engineering 2007;54:597-610

8. Ursino M, Lodi CA, Russo G: Cerebral hemodynamic response to $\mathrm{CO} 2$ tests in patients with internal carotid artery occlusion: modeling study and in vivo validation. Journal of Vascular Research 2000;37:123-133 
9. Vinecore K, McNames J, Aboy M, Phillips C, Agbeko R, Peters M, et al.: Design and Implementation of a Portable Physiologic Data Acquisition System For Research. Ped Crit Care Med 2007: (in press)

10. Almog Y, Eldor S, Oz O, Akselrod S: Beat-to-beat fluctuations in the BP related signals in rats: can it contribute to the understanding of the development of hypertension? $J$ Auton Nerv Syst 1998;69:39-48

11. Wakeland W, Fusion J, Goldstein B. Estimation of subject-specific ICP dynamics models using prospective clinical data. In: Ursino M, Brebbia C, Pontelli G, Magosso E, editors. Modeling and Biology IV. S. Hampton, Boston: WIT Press; 2005. p. 57-66

12. Wakeland W, Goldstein B: A computer model of intracranial pressure dynamics during traumatic brain injury that explicitly models fluid flows and volumes. Acta Neurochirguca 2005;95:321-326

13. Wakeland W, McNames J, Goldstein B. Calibrating an intracranial pressure dynamics model with annotated clinical data: a progress report. . In: Annual Int'l Conf. of IEEE Engr. in Medicine and Biology. San Francisco, California: IEEE; 2004. p. 746-749

14. Wakeland W, Goldstein B: A review of physiological simulation models of intracranial pressure dynamics. Computers in Biology and Medicine 2007; under review

15. Czosnyka M, Piechnik S, Richards HK, Kirkpatrick P, Smielewski P, Pickard JD: Contribution of mathematical modelling to the interpretation of bedside tests of cerebrovascular autoregulation. Journal of Neurology, Neurosurgery \& Psychiatry $1997 ; 63: 721-731$

16. Ursino M, Magosso E: Role of tissue hypoxia in cerebrovascular regulation: a mathematical modeling study. Annals of Biomedical Engineering 2001;29:563-574 
17. Ursino M, Lodi CA: A simple mathematical model of the interaction between intracranial pressure and cerebral hemodynamics. Journal of Applied Physiology 1997;82:1256-1269

18. Hoffmann O: Biomathematics of intracranial CSF and haemodynamics. Simulation and analysis with the aid of a mathematical model. Acta Neurochirurgica - Supplementum 1987;40:117-130

19. Lodi CA, Ter Minassian A, Beydon L, Ursino M: Modeling cerebral autoregulation and $\mathrm{CO} 2$ reactivity in patients with severe head injury. American Journal of Physiology 1998;274:H1729-1741

20. Ursino M, Iezzi M, Stocchetti N: Intracranial pressure dynamics in patients with acute brain damage: a critical analysis with the aid of a mathematical model. IEEE Transactions on Biomedical Engineering 1995;42:529-540

21. Ursino M, Ter Minassian A, Lodi CA, Beydon L: Cerebral hemodynamics during arterial and $\mathrm{CO} 2$ pressure changes: in vivo prediction by a mathematical model. American Journal of Physiology - Heart \& Circulatory Physiology 2000;279:H2439-2455 


\section{Figure Legends}

Figure 1. Impact of head of bed elevation $(\mathrm{HOB})$ and respiratory rate $(\mathrm{RR})$ changes on intracranial pressure (ICP).

Figure 2. Parameter estimation process using an optimization algorithm to find the "best fit" parameter values.

Figure 3. Overview of methodology to assess model prediction capability.

Figure 4. Thumbnail images of each session and the predicted ICP using individually fit parameter values listed in Table 1. The individual plot numbers correspond to those in Table $\mathbf{1 .}$ The recorded ICP waveform is the green jagged trace. The modeled ICP is the non-jagged blue trace. The red and black traces at the bottom show changes in the HOB and ventilation rate, respectively.

Figure 5: Fluid flow concept diagram for ICP Dynamic model

Figure 6: Simulink implementation of ICP dynamic model. The primary state variables are the six volumes (arterial, brain, capillary, CSF, hematoma, and venous), represented by the green shadowed "flowchart" icons. Each of the flowchart icons in this figure represents a masked subsystem containing additional model logic. 
Appendix. Details regarding the ICP dynamic model

Figure 5 shows the primary volumes and flows, except brain volume, which must be accounted for, but does not participate in the flow processes.

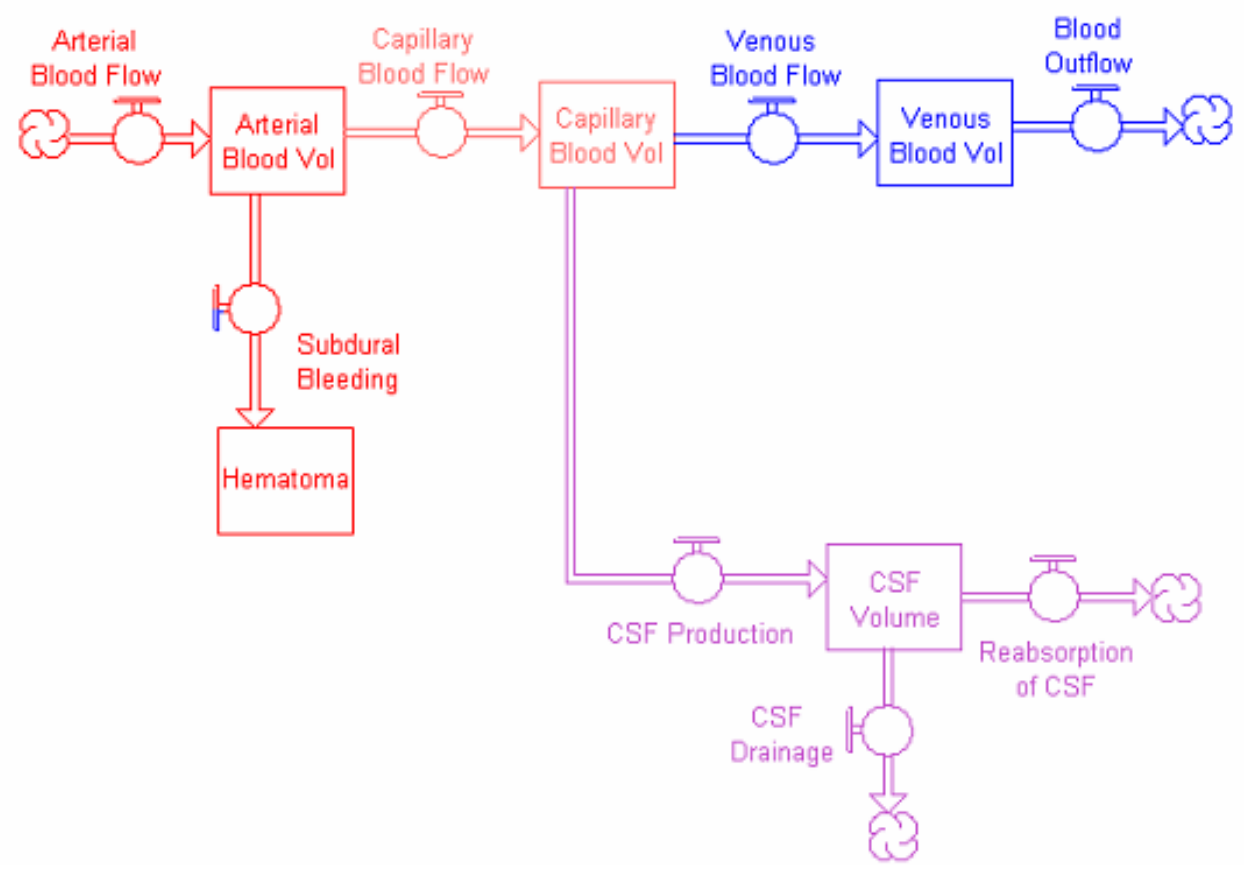

Figure 5: Fluid flow concept diagram for ICP Dynamic model

Basic Pressure Logic

- Intracranial Pressure $(\mathrm{ICP})=$ Base ICP $\times 10^{\wedge}($ Total Cranial Volume-Base Cranial Volume)/PVI

$\rightarrow$ Total Cranial Volume $=\mathrm{ABV}+\mathrm{CBV}+\mathrm{VBV}+\mathrm{CSF}+\mathrm{BV}+\mathrm{HV}$

$\rightarrow$ PVI (pressure-volume index) is the amount of added fluid that would cause pressure to increase by a factor of 10

- Arterial, capillary, and venous pressures

$\rightarrow \mathrm{Pab}=\mathrm{ICP}+(\mathrm{ABV}) /($ Arterial Compliance $)$

$\rightarrow \mathrm{Pcb}=\mathrm{ICP}+(\mathrm{CBV}) /($ Capillary Compliance $)$

$\rightarrow \mathrm{Pvb}=\mathrm{ICP}+(\mathrm{VBV}) /($ Venous Compliance $)$

Basic Autoregulation (AR) Logic

- Arteriolar to capillary resistance changes in order to maintain needed blood flow rate

$\rightarrow$ Higher resistance $=$ constriction

$\rightarrow$ Lower resistance $=$ dilation

$\rightarrow$ A time constant characterizes the adjustment process

- Typically 2-3 minutes (estimated from patient response data)

$\rightarrow$ Resistance is asymmetrically bounded by minimum and maximum values

- Cerebrovasular AR responds to multiple stimuli

$\rightarrow$ Changing Metabolic needs (e.g., asleep vs. awake)

$\rightarrow$ Changing the $\mathrm{HOB}$, changing RR, etc. 
Figure 6 shows the model, as implemented in Simulink. The state variables in the model are the volumes of the various fluid compartments. Changes in these volumes cause changes in pressure. Pressure changes affect the flows, which in turn impact the volumes. These feedback loops dominate the behavior of the model, and the most influential of them is the ICP loop itself. ICP is a function of the sum of the six volumes in the model. ICP also directly influences four of those volumes: arterial blood, capillary blood, CSF, and venous blood. The other two volumes, representing the brain parenchyma and hematoma, influence ICP but are not influenced by ICP in our model. The inputs from the physiologic challenge protocol are each simulated in the model by specific blocks for that purpose. 


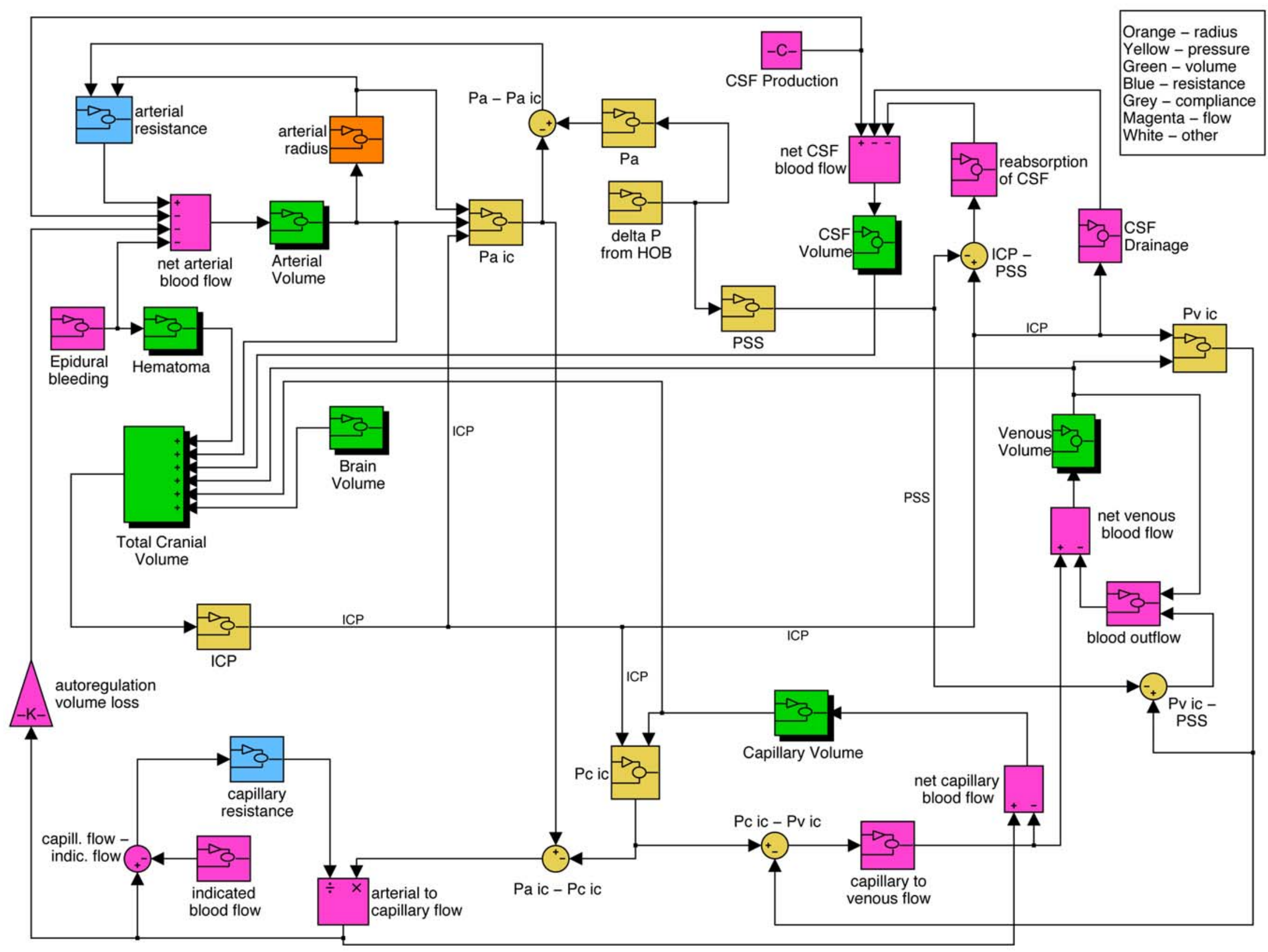

Figure 6: Simulink implementation of ICP dynamic model. The primary state variables are the six volumes (arterial, brain, capillary, CSF, hematoma, and venous), represented by the green shadowed "flowchart" icons. Each of the flowchart icons in this figure represents a masked subsystem containing additional model logic. 